\title{
Positive Relationships as an Indicator of Flourishing During Emerging Adulthood
}

\author{
Laura M. Padilla-Walker \\ Madison K. Memmott-Elison \\ Larry J. Nelson \\ Brigham Young University - Provo, larry_nelson@byu.edu
}

Follow this and additional works at: https://scholarsarchive.byu.edu/facpub

Part of the Other Social and Behavioral Sciences Commons

\section{Original Publication Citation}

Padilla-Walker, L. M., Memmott-Elison, M. K., \& Nelson, L. J. (2017). Positive Relationships as an Indicator of Flourishing During Emerging Adulthood. In L. M. Padilla-Walker and L. J. Nelson (Eds.), Flourishing in emerging adulthood: Positive development during the third decade of life pp. 212-236. New York, NY: Oxford University Press.

\section{BYU ScholarsArchive Citation}

Padilla-Walker, Laura M.; Memmott-Elison, Madison K.; and Nelson, Larry J., "Positive Relationships as an Indicator of Flourishing During Emerging Adulthood" (2017). Faculty Publications. 4717.

https://scholarsarchive.byu.edu/facpub/4717

This Book Chapter is brought to you for free and open access by BYU ScholarsArchive. It has been accepted for inclusion in Faculty Publications by an authorized administrator of BYU ScholarsArchive. For more information, please contact ellen_amatangelo@byu.edu. 


\title{
8 \\ Positive Relationships as an Indicator of Flourishing During Emerging Adulthood
}

\author{
LAURA M. PADILLA-WALKER, \\ MADISON K. MEMMOTT-ELISON, AND LARRY J. NELSON
}

In any discussion about flourishing in emerging adulthood, it would be easy to simply think about the positive things that young people do (e.g., pursue education, volunteer, serve, engage in political activism). However, few emerging adults walk the path toward adulthood alone. They embark on and make their way through the third decade of life within a myriad of complex relationships with family, friends, and romantic partners. However, the changing nature of these relationships is arguably more complex than at any other point in their lives to date. Graduation (for most) from high school brings the dissolution of many peer groups as young people begin their varied paths toward their future (e.g., college, military, career).

Some friendships may endure, but many young people begin the task of forming a new set of friends and romantic partners that will play important roles in the next phase of their lives. Relationships with family members change as the desire for greater autonomy and the need to become self-reliant leads to changes in both the physical and emotional closeness of parents and children. The way in which young people navigate these changing relationships, and the new patterning of relationships that are formed, may play important roles in the extent to which young people flourish during the third decade of life. The purpose of this chapter is to examine the role that relationships with members of one's family of origin (parents, grandparents, and siblings) and with peers (romantic partners, spouses, and friends) play in flourishing during emerging adulthood. 


\section{A Theoretical Considerations}

There are a number of theoretical models that help us to understand the importance of relationships during emerging adulthood and how having healthy relationships is central to flourishing. The centrality of family relationships during emerging adulthood is best explained by examining both continuity (social learning theory and attachment theory) and change (life course perspective) in relationships over time. Social support theories also provide insight into how emerging adults might balance different relationships in an effort to meet their needs. It is not our goal here to place different relationships at odds with one another (e.g., which relationship is most important), but rather to argue that each type of relationship discussed serves an important and sometimes unique function that contributes to overall flourishing. If one type of relationship is lacking, other relationships often makes up the difference, but the important point we argue in this chapter is that relationships are valuable during emerging adulthood.

Social learning (Whitbeck, Hoyt, \& Huck, 1994) and attachment theory suggest that early patterns of interaction with family members and friends will continue to impact relationships during emerging adulthood (Aquilino, 2006). Patterns of interactions that are established and maintained during the formative years will be modeled to some degree as emerging adults leave the parental home and establish new relationships and, ultimately, families of their own. Though internal working models of attachment may change over time, the attachment relationship that is formed early in life will generally remain stable and, in turn, influence the formation of relationships during emerging adulthood (Fraley \& Roisman, 2015). Indeed, research has found a moderate level of continuity in the parent-child relationship in particular over the transition to adulthood (Englund, Kuo, Puig, \& Collins, 2011), though this is certainly not the case for all emerging adults, and there are a number of transitions that may impact attachment quality for better or worse.

In terms of change in relationships over time, a life course perspective suggests that the trajectories of family members are interdependent and there is a consistent interplay between the individual development of the emerging adult child and his or her family members (Aquilino, 2006). This interplay is based on two main processes, namely that (a) family relationships change over time as a function of 
the development of individuals in that family, and (b) life trajectories of family members are influenced by the changes in family relationships over time. As emerging adults leave the family home, many of their relationships may change and begin a new period of development wherein emerging adults and siblings, parents, and grandparents interact in new ways, thus impacting the positive trajectory of emerging adult children. As children become adults, and as parents and grandparents move into different stages of life, relationships remain important but also will be somewhat redefined and renegotiated (Sheehan \& Petrovic, 2008). A life course perspective suggests that as emerging adult children experience different life transitions (e.g., college, work, marriage, parenthood), these life experiences will impact the family system and relationship quality with others, especially with family members. For example, emerging adults leaving the parental home and going far away to college or work may result in more physical and emotional distance from family relationships. Although marriage during emerging adulthood should naturally result in a shift in cohesion from family to spouse, becoming a parent may then result in a closer relationship to parents and grandparents. Thus, life transitions that emerging adults experience should naturally impact relationships with others, but the maintenance of quality relationships across the life course despite transitions may be key to flourishing trajectories during this time of change.

There are also models of social support that inform the nature of relationships during emerging adulthood. In terms of how emerging adults balance different relationships between family members and peers, the hierarchical-compensatory model of relationships (Cantor, 1979; Li \& Cheng, 2015) suggests that adults have a preferred source of support across all domains, and only when that preferred source is not available will they turn to another source of support. Family members (parents, siblings) are usually those who are primary sources of social support, while friends play a more minor role. While this theory has been supported with numerous adult samples, it may not be as accurate for a nonmarried emerging adult who places more emphasis on social support from friends. Indeed, the task-specific model of social support (Messeri, Silverstein, \& Litwak, 1993) suggests that young adults may actually prefer different sources of social support, depending on the need they are currently experiencing. For example, emerging adults may turn to family for certain needs, especially needs that are more chronic (e.g., monetary stress), whereas they may turn to friends 
for needs that are a function of shared life experiences or interests (e.g., loneliness).

Related to this model, the functional specificity model of relationships suggests that relationships are not only a matter of preference and need, but also may serve very distinct functions in the lives of emerging adults (Simons, 1983). This model posits that the needs of security, intimacy, and self-esteem are the basic needs that are filled by relationships, and that different relationships fill these needs in unique ways. For example, parent-child relationships may be especially important for feelings of security during the transition to adulthood, romantic relationships may be critical for intimacy, and friendships may enhance selfesteem. Although these three theories are not in direct conflict with one another, they do all support the importance of relationships across the life course, and they suggest that relationships are a necessary form of social support. In this chapter we will first discuss family relationships, including relationships with parents, siblings, and related kin. Then we will discuss romantic relationships and friendships, and argue that each type of relationship fills important needs during emerging adulthood.

\section{A Family Relationships}

In general, family relationships are among those most consistently associated with flourishing across the life course, and emerging adulthood is no exception to this pattern. Perceived social support from family (Brannan, Biswas-Diener, Mohr, Mortazavi, \& Stein, 2013), feelings of family closeness (Taylor, Chatters, Hardison, \& Riley, 2001), and centrality of family to one's identity (Crocetti \& Meeus, 2014) have all been consistently associated with flourishing during emerging adulthood. More specifically, social support from family is positively associated with subjective well-being, happiness (Brannan et al., 2013; Taylor et al., 2001), and life satisfaction (Crocetti \& Meeus, 2014), and negatively associated with depression (Sheets \& Mohr, 2009) during the transition to adulthood. The importance of social support from family is consistent for both males and females (Crocetti \& Meeus, 2014) and among college and non-college emerging adults (Crocetti \& Meeus, 2014). Findings are also consistent across a number of different racial, ethnic, and minority groups, including Italians (Crocetti \& Meeus, 2014), African Americans (Taylor et al., 2001) and sexual minorities (Sheets \& Mohr, 2009), though 
research suggests that the salience of family may be even more striking for some ethnic groups, such as Asian (Li \& Cheng, 2015), Filipino, and Hispanic (Fuligni \& Pedersen, 2002) emerging adults. These studies highlight the importance of considering the role of family support in a multidimensional fashion, with special attention paid to gender, culture, and college versus non-college populations. While the family relationship in general, and support from family specifically, has been found to be associated with indicators of flourishing, different family relationships may be differentially related to positive outcomes. Thus, in this chapter we will focus on the parent-child relationship, the sibling relationship, and relationships with extended kin during emerging adulthood.

\section{Parent-Child Relationship}

Of family relationships, the parent-child relationship clearly stands out as the most commonly studied during emerging adulthood. Though the majority of emerging adults leave the parental home some time before achieving adulthood, the parent-child relationship continues to be a central aspect of flourishing during this transition. Not surprisingly, strong parent-child ties during emerging adulthood are predicted by strong ties during adolescence (Aquilino, 2006; Englund et al., 2011), but for many families the transition to adulthood is challenging, and both parents and children may experience a few growing pains as the roles become somewhat blurred. In unique cases, relationships may be improved by creating physical distance from controlling parenting, while others may experience a decrease in closeness with parents as a result of moving out of the parental home. Despite variability, research suggests that the majority of emerging adults enjoy a relatively stable and positive relationship with parents across the transition to adulthood (van Wel, Linssen, \& Abma, 2000), and that this is a clear sign of flourishing associated with an overall positive trajectory through this time period (Nelson \& Padilla-Walker, 2013).

Research during emerging adulthood suggests that parental closeness/support and control/conflict are the two most salient aspects of the parent-child relationship during the transition to adulthood (Aquilino, 1997). Though a number of studies examine continuity between parenting during adolescence and outcomes during emerging adulthood, for 
the purposes of this chapter we focus primarily on how the parent-child relationship during emerging adulthood is evidence of flourishing (e.g., Nelson \& Padilla-Walker, 2013).

When considering closeness, the literature has primarily assessed the general constructs of parent-child relationship quality and parental support as indicators of closeness or a positive parent-child relationship, though a few studies have also considered specific parenting dimensions or practices. In terms of relationship quality, findings suggest that a positive parent-child relationship is associated with more happiness and less depression (Cheng \& Furnham, 2003), fewer sexual hookups (Johnson, 2013), and lower levels of alcohol use across emerging adulthood (Serido, Lawry, Li, Conger, \& Russell, 2014). Maternal relationship quality is also associated with higher levels of prosocial values, religious faith (Barry, Padilla-Walker, \& Nelson, 2012), prosocial behavior (Barry, Padilla-Walker, Madsen, \& Nelson, 2008), and perceived happiness (Demir, 2010). In turn, relationship quality or closeness with fathers is uniquely associated with emerging adults' happiness, life satisfaction, and psychological distress (Amato, 1994), though markedly fewer studies have considered the role of fathers in the lives of emerging adults as compared to mothers. Similar to findings with general relationship quality, perceived parental support is associated with well-being (Helgeson et al., 2014) and higher GPA among college students (Cutrona, Cole, Colangelo, Assouline, \& Russell, 1994), as well as being longitudinally associated with psychological adjustment during the transition to college (Holahan, Valentiner, \& Moos, 1994).

A few studies have also considered more nuanced aspects of parenting and found that attachment to parents (Laible, Carlo, \& Roesch, 2004) and mutual reciprocity (Wintre \& Yaffe, 2000) are associated with higher self-esteem and positive adjustment, as well as lower levels of drinking and drug use (Cerdá et al., 2014), while parent-child affective quality is negatively associated with substance use (Ralston, Trudeau, \& Spoth, 2012). Taken together, we can conclude that a positive parent-child relationship is associated with a number of evidences of flourishing during emerging adulthood, including overall well-being and self-esteem, while also protecting against behavior that may be indicative of floundering, including drug use and depression. Studies suggest that parental support may be particularly important for those emerging adults transitioning to college, though few of these studies included non-college populations. 
Parental control is another aspect of the parent-child relationship that is salient during this time period and that has been assessed in a variety of different ways. A person-centered approach to parenting during emerging adulthood suggested that about $17 \%$ of mothers and $7 \%$ of fathers were characterized as highly controlling, while another $22 \%$ of mothers had above average scores on parental control (Nelson, Padilla-Walker, Christensen, Evans, \& Carroll, 2011). More controlling parents had emerging adult children with lower levels of self-worth and higher levels of depression and anxiety than did emerging adults with less controlling parents. Consistent with these findings, studies have also found that parental control during emerging adulthood is associated with depression, smoking behavior (Helgeson et al., 2014), and lower levels of child-disclosure (Urry, Nelson, \& Padilla-Walker, 2011). A particularly harmful form of parental control is psychological control (i.e., parental behaviors that are intrusive and manipulative of children's thoughts, feelings, and attachment to parents, such as invalidating feelings, love withdrawal, inducing guilt; Barber \& Harmon, 2002). Psychological control of emerging-adult children has been tied to lower relationship satisfaction with mother and greater participation in risk behaviors (Urry et al., 2011), as well as problematic identify formation (Luyckx, Soenens, Vansteenkiste, Goossens, \& Berzonsky, 2007).

Similarly, helicopter parenting, a specific type of parental control characterized by parents' over-involvement in the lives of their children, has been linked to lower levels of school engagement (Padilla-Walker \& Nelson, 2012), satisfaction with family life (Segrin, Woszidlo, Givertz, Bauer, \& Murphy 2012), and life satisfaction, as well as higher levels of depression and psychological distress (Schiffrin et al., 2014) and more pessimistic views of marriage (Willoughby, Hersh, Padilla-Walker, \& Nelson, 2015). Helicopter parenting seems to be particularly problematic in the absence of parental warmth, when it is then associated with low self-esteem and high-risk behaviors (Nelson \& Padilla-Walker, 2013).

It is clear from these studies that parental control is not adaptive during emerging adulthood, and it might be accurate to boldly say that no control (not even appropriate behavioral control) is helpful for emerging adults, despite the fact that at least a portion of emerging adult college students think their parents do have some legitimate control over their lives (Padilla-Walker, Nelson, \& Knapp, 2014). Given that autonomy-supportive parenting is associated with subjective wellbeing (Ratelle, Simard, \& Guay, 2013) and longitudinally with lower 
levels of depressive symptoms (Van der Giessen, Branje, \& Meeus, 2014), it is most clear that supportive, strong parent-child relationships are crucial to flourishing during emerging adulthood, while controlling or distant relationships are detrimental.

Although there is a growing body of research examining the positive and negative correlates of the parent-child relationship during emerging adulthood, there are still a great many unanswered questions. Though an increasing number of studies suggest parenting during the third decade of life is meaningfully different than at prior developmental periods, many studies still use college samples as convenience samples and fail to make strong developmental conclusions. This raises two points: first, the ever-important need to consider noncollege samples, and second, the lack of understanding regarding how parenting might be unique during emerging adulthood. We know virtually nothing, for example, about how parents might be differentially important for college vs. non-college emerging adults. It is possible that parental involvement, particularly financial involvement, may be more salient for college-bound emerging adults, given the rising prices of college tuition, but other aspects of parental involvement are likely just as important (or more important) for emerging adults who do not attend or who drop out of college.

The field also would benefit greatly from a more nuanced and multidimensional approach to parenting during this time period, with longitudinal studies that can help us see how parenting might change over the transition to adulthood and how we might need to change measurement strategies to more accurately tap into these nuances. Similarly, there is virtually no research on the parent-child relationship among ethnic, racial, or sexual minorities during the transition to adulthood, which seems a very fruitful avenue, considering the variability of trajectories through adulthood for different minority groups. While we certainly need more research on helicopter parenting and similar aspects of maladaptive parenting during emerging adulthood, we also call for more research on the diverse aspects of positive mothering and fathering (e.g., autonomy support, various types of involvement, warmth) that are likely to more strongly support outcomes indicative of flourishing during this time period. Similarly, research on parenting would benefit from looking at outcomes that go beyond general measures of self-esteem, well-being, or lack of drug use. For example, what is the role of the parent-child relationship on emerging adults' civic and political 
engagement, moral identity, values, work ethic, leadership, family formation, and sense of purpose? These are just a few possibilities.

\section{Sibling Relationships}

Another family relationship that may provide unique support during the transition to adulthood is the sibling relationship. Sibling relationships are among the longest relationships individuals have, often extending from childhood through late adulthood (Scharf \& Shulman, 2015). Though a relatively understudied topic overall, there is a particular paucity of research examining sibling relationships during emerging adulthood. For most individuals, the sibling relationship undergoes significant changes when the oldest sibling moves out of the family home and the relationship becomes much more voluntary. While for some siblings this results in more distance, for many the sibling relationship remains a source of support and advice, without the conflict that might have been more common when the children lived under the same roof.

Research that has examined siblings during emerging adulthood suggests that sibling relationships are among the most satisfying aspects of life during this time period (Chow, 2005), and emerging adults who spend time with siblings report above average levels of happiness (Csikszentmihalyi \& Hunter, 2003). The most common aspects of the sibling relationship studied have been sibling support and the quality of sibling relationships (e.g., support, nurturance, helping, identification with sibling). These studies have found that a quality relationship with a sibling during emerging adulthood is associated with high levels of well-being (Sherman, Lansford, \& Volling, 2006), competence (Hollifield \& Conger, 2015), life satisfaction, and self-esteem (Milevsky, 2005). Sibling relationship quality is also associated with lower levels of drug use (for younger male siblings with older brothers; Brook, Brook, \& Whiteman, 1999), loneliness (Milevsky, 2005), and depression. One study also found that emerging adults disclose more information to siblings than do adolescents, and that this open disclosure is associated with greater sibling relationship satisfaction and lower depression (Campione-Barr, Lindell, Giron, Killoren, \& Greer, 2015), though results vary as a function of sibling age and gender. Some studies suggest that sibling relationships can be compensatory for low levels of parent and peer support (Milevsky, 2005), though other studies have not found siblings to compensate for poor peer relationships (Sherman et al., 2006). 
Taken together, it seems clear that positive sibling relationships are an important indicator of flourishing for many emerging adults. Clearly, there are numerous additional avenues for future research in this area, with specific attention being needed on how siblings might help emerging adults achieve some of the developmental tasks characteristic of this time period. Many of the studies on sibling relationships during this time period treat emerging adults as a convenience sample of college students, and so may not address developmentally relevant issues. For example, it might be interesting to examine the role of siblings on the transition from home to college or work, on identity formation, on romantic relationship formation, and on the transition to parenthood. Given the physical distance that may exist between siblings as they leave the parental home, research should distinguish between siblings who are close geographically and those who are not, biological versus step siblings, as well as considering typical sibling variables such as gender makeup of the dyad, birth order, age gap between siblings, and the role of having more than one sibling. Our knowledge of how siblings might contribute to flourishing during the third decide of life is clearly in its infancy, as is research on how family members outside the immediate family may also serve as a source of support.

\section{Extended Family Relationships}

A small body of research examines the role of nonresidential grandparents and extended kin in the lives of adolescents and emerging adults. Research suggests that emotional closeness with a grandparent during adolescence is associated with fewer adjustment difficulties (AttarSchwartz, 2015), lower levels of emotional and behavioral problems (Tanskanen \& Danielsbacka, 2012), and higher levels of prosocial behavior (Yorgason, Padilla-Walker, \& Jackson, 2011). Research also suggests the importance of considering the geographical distance between grandparents and grandchildren (Yorgason et al., 2011) and the role of the grandparent-parent relationship (Attar-Schwartz, 2015) when considering the influence of grandparents on their grandchildren.

Though grandparents are important during the formative years, we know less about the role of extended family once children leave the parental home. It is possible, given the increased emotional, cognitive, and financial demands of emerging adulthood, that grandparents become an even more important source of support than at earlier time 
periods for some emerging adults. However, it is also possible that with the role transitions inherent in this developmental time period relationships become more distant. Indeed, research suggests that contact with grandparents decreases during adolescence and beyond, in part because contact is now up to the grandparents and grandchild instead of the parent (Scharf, 2015). Although there are few studies that can help us definitively make a conclusion about the significance of grandparents, existing research does suggest that grandparents may help to facilitate flourishing during emerging adulthood. Similar to research during adolescence, findings suggest that grandmothers (especially maternal grandmothers) generally provide the greatest source of support for their emerging-adult grandchildren (Block, 2002). Though a variety of types of grandparent involvement have been assessed, emotional closeness (i.e., affection, relationship quality) has been the most consistently linked with positive outcomes for emerging adults. More specifically, emotional closeness with a grandparent has been associated with fewer psychological symptoms (Henderson, Hayslip, Sanders, \& Louden, 2009), less social isolation and fear of intimacy (Mansson \& Booth-Butterfield, 2011), and lower levels of stress, depression, and loneliness during emerging adulthood (Mansson, 2013). Emotional closeness with a grandparent also promotes relational competence, self-efficacy (Henderson et al., 2009), and social activity (Mansson \& Booth-Butterfield, 2011). Many of the protective factors associated with the grandparent relationship were stronger for emerging adults from divorced (Henderson et al., 2009) or singleparent families (Ruiz \& Silverstein, 2007), suggesting that relationships with extended family may be especially important for those emerging adults who do not have the support of both parents.

Although there is a small body of research examining the role the extended family may play in promoting positive trajectories for emerging adults, certainly more research is needed in this area. First, given the life course perspective and the changes that may take place in relationships during this time period as a function of transitions, longitudinal research should examine relationship changes as emerging adults transition and achieve developmental tasks such as finishing college, finding a job, or getting married, and as grandparents transition to roles such as retirement and the facing of potential health issues. Research also suggests that extended family relationships may be a particularly important source of support for those from single-parent or divorced families, suggesting the need for more diverse samples in relation to 
family structure, income, and ethnicity in an attempt to understand the nuances of these relationships for diverse emerging adults. The field would also benefit from research on other types of extended family members beyond grandparents, such as aunts and uncles (Langer \& Ribarich, 2007), who have also been shown to have a positive impact on flourishing during emerging adulthood.

It is clear that family relationships remain a central influence in the lives of emerging adults and are associated with a host of positive outcomes, as described above, but most emerging adults also develop relationships with those outside their family as they seek to meet their intimacy and autonomy goals. The next section of this chapter will focus on romantic and friendship relationships as two key examples of non-family-of-origin relationships that are central to flourishing during the third decade of life.

\section{A Romantic Relationships}

Research suggests emerging adulthood is a time where engagement in romantic relationships is especially critical in the process of positive development (Collibee \& Furman, 2015). Although romantic relationships can be positive, some research indicates that certain types of romantic relationships in emerging adulthood can be harmful to individual development. For instance, casual sexual relationships (CSRs) are an increasingly popular phenomenon in emerging adulthood, but they can be problematic and lead to psychological worries (e.g., regret about being used, worries about pregnancy for women, concerns about lost reputation; Campbell, 2008; Eshbaugh \& Gute, 2008), early sexual transition (Grello, Welsh, \& Harper, 2006), and depressive symptoms (Owen, Fincham, \& Moore, 2011). Approximately 60\% of emerging adults report engaging in a CSR at least one time (e.g., Jonason, Li, \& Cason, 2009), though it is noteworthy that most samples consist primarily of college student participants.

On the other hand, research suggests that romantic relationship formation is an integral focus from adolescence to emerging adulthood, as $70 \%$ of individuals have engaged in a dating relationship by age 18 (Carver, Joyner, \& Udry, 2003) and approximately 80\% of adults marry at least one time before age 40 (Settersten \& Ray, 2010). Research reveals being in a romantic relationship in emerging adulthood is related to 
greater well-being (Adamczyk \& Segrin, 2014) and quality of life, as well as less anger and sadness (Gala \& Kapadia, 2013). Notably, the effects of dating and cohabitation tend to vary consistently by gender. For instance, some research shows that being in a dating relationship in college is linked with fewer depressive symptoms (Whitton, Weitbrecht, Kuryluk, \& Bruner, 2013) and greater well-being (Soons \& Liefbroer, 2008) for college-attending women, but not for college-attending men, and that women, but not men, experience improved emotional health when they make the decision to cohabit with their partner (Mernitz \& Dush, 2016). This may be due to women perceiving dating and cohabitation as distinct indicators of increased commitment, while men do not share this perspective to the same degree (Rhoades, Stanley, \& Markman, 2006). However, more research is needed in order to fully substantiate these assertions.

A large portion of the romantic relationship literature focuses not only on whether an individual is in a relationship or not, but also on the quality of such relationships. Research indicates having good relationship quality with one's partner is linked to increased self-esteem (Elliott, 1996) and happiness (Demir, 2008), providing evidence that favors the facilitation of self-assurance within the context of romantic relationships. Additional research shows taking a multidimensional approach when studying relationship quality provides richer descriptions regarding how relationships are associated with individual development. Specifically, in one study, four qualities of committed romantic relationships (i.e., companionship, worth, affection, and emotional support) were associated with emerging adults' identity achievement (Barry, Madsen, Nelson, Carroll, \& Badger, 2009). Another study found that warmth, structure, and autonomy support present in a romantic relationship context were related to well-being and life fulfillment for emerging adults (Ducat \& Zimmer-Gembeck, 2010), confirming the importance of assessing qualities of positive romantic relationships, rather than focusing only on relationship status or having "good" relationship quality.

A coherent and consistent literature exists that evidences involvement in positive romantic relationships serves as a protective factor against negative correlates in emerging adulthood (Berge, Bauer, MacLehose, Eisenberg, \& Neumark-Sztainer, 2014). For instance, research reveals that being in a committed romantic relationship and having positive relationship quality is associated with both decreased mental health problems (i.e., anxiety and depressive symptoms; 
Whitton \& Kuryluk, 2012; Yu, Branje, Keijsers, \& Meeus, 2015) and physical health problems (Braithwaite, Delevi, \& Fincham, 2010). One possible explanation for linkages between romantic relationship involvement and protection against health problems is that being in a romantic relationship is associated with having fewer sexual partners, which is then inversely related to problematic outcomes such as anxiety. Or perhaps having a romantic partner increases well-being, which then decreases health problems (Adamczyk \& Segrin, 2014). In addition, being in a romantic relationship both requires and facilitates the development of behavioral regulation, which in turn likely reduces problematic or otherwise unhealthy behaviors. It is notable that the extant literature necessitates further research in order to illuminate other protective factors associated with being in a relationship in addition to health-related effects, which are the main focus of current research. However, one study conducted by Furman and Collibee (2014) did just this, and found that romantic partner involvement in emerging adulthood was related to decreased internalizing, externalizing, and substance abuse behaviors. It is likely that greater emotional health or well-being mediates these associations, though more research is clearly needed in order to justify this claim.

Regarding marriage, most emerging adults desire to eventually marry, but are cautious regarding the permanence of marital relationships (Willoughby \& Hall, 2015). These attitudes about marriage are evident in the rising age of first marriage (27 for women and 29 for men) as well as the increase in cohabitation as an alternative or precursor to marriage for the majority of couples (Hymowitz, Carroll, \& Wilcox, 2013). Most emerging adults will eventually marry, so it is important to understand associated thoughts and experiences that accompany this life event.

Some scholarly work shows male and female emerging adults report equal emotional advantages within marriage (Simon \& Barrett, 2010), experiencing less disordered eating (Keel, Baxter, Heatherton, \& Joiner, 2007) and depressive symptoms (Galambos, Barker, \& Krahn, 2006), as well as increased satisfaction (Whitton \& Kuryluk, 2012). Not surprisingly, research suggests marriage is a clearer sign of flourishing in middle-to-late emerging adulthood (mid-twenties) than in early emerging adulthood (age 21 or younger, Hamilton, 2012), possibly because those in later emerging adulthood have gained greater dating and relationship experience, resulting in a more confident partner choice. 
There are certainly reasons to consider potential gender differences in the role that marriage plays in the lives of young people (for a more comprehensive review, see Chapter 4 , this volume). For instance, research has shown that while women perceive their marriages more negatively than men, on average, men and women can both find happiness in committed relationships (i.e., marriage) when couple interactions, expectations, and perceptions by gender are taken into account (Boerner, Jopp, Carr, Sosinsky, \& Kim, 2014). Indeed, studies have shown that marriage can benefit both men and women, with married people being generally happier, less depressed, more economically stable, and more satisfied with life (Scott et al., 2009; Stack \& Eshleman, 1998; Wood, Goesling, \& Avellar, 2007), though the levels and specific outcomes vary by gender (e.g., marriage lowers men's risk for depression and panic disorders, whereas for women it reduces the risk of substance abuse; Scott et al., 2009). Thus, the findings regarding marriage for men and women, respectively, are complex. Unfortunately, little research exists that analyzes the effects of marriage by gender in emerging adulthood; that is, most research focuses on gender differences within CSR's, dating, and cohabiting relationships during this time period, since these types of relationships are more normative during emerging adulthood. As such, we suggest future researchers consider whether the effects of marriage vary by gender in emerging adulthood.

Taken together, it appears that romantic relationship involvement and positive relationship quality in emerging adulthood both enable the development of positive behaviors and protect against negative behaviors. As such, there is sufficient evidence that shows engagement in committed romantic relationships can be a particularly healthy, enabling process for emerging adults, although this research may be somewhat limited in breadth (Eccles, Templeton, Barber, \& Stone, 2003). It is of note that only a scant amount of literature explicitly focuses on positive aspects of engaging in relationships during emerging adulthood-as such, more research is needed in order to understand the positive outcomes associated with being in a romantic relationship during this time period.

\section{A Friendships}

In addition to romantic relationships, friendships hold deep sentiment and meaning in emerging adults' lives, therefore serving as another indicator of flourishing during this time period. Friendships are often 
categorized as consensual, nonbiologically based relationships that contain high amounts of prosocial behavior, personal disclosure, praise after success, and encouragement after failure, as well as low amounts of conflict and rivalry (Berndt, 2002). Some suggest there are five main dimensions of friendships (closeness, companionship, conflict, help, and security), which are critical indicators of friendship importance from adolescence to emerging adulthood (Ponti, Guarnieri, Smorti, \& Tani, 2010). Friendships have been shown to be important to emerging adults across cultures, including populations such as the United States, Jordan (Brannan et al., 2013), Asia (Demir, Jaafar, Bilyk, \& Mohd Ariff, 2012), Latin America (Garcia, Pereira, \& de Macedo, 2015), and among the Dine, a Native American tribe (Willeto, 2015). Therefore, friendships contribute to flourishing for a wide variety of emerging adults.

Research indicates that friendships may be particularly salient indicators of flourishing during emerging adulthood, as both quality (Demir, Özdemir, \& Weitekamp, 2007) and quantity (Carmichael, Reis, \& Duberstein, 2015) of friendship interactions have been shown to be associated with positive outcomes. Indeed, research suggests that the functionality of friendships changes from adolescence to emerging adulthood, when young adults begin to confide in and refer to friends at the same rate or more than family members for advice regarding life choices (Tanner, 2011). In addition, positive friendships have been shown to buffer against negative effects of having lower-quality relationships with members of one's family, particularly siblings (Sherman et al., 2006). Research also shows that both young men and women benefit from high-quality friendships (Almquist, Östberg, Rostila, Edling, \& Rydgren, 2014), but other research clarifies findings and shows women report receiving more benefits of friendship, having higher relationship quality (Barry, Chiravalloti, May, \& Madsen, 2013), experiencing lower conflict, and having smaller discrepancies in reported friendship quality (Demir \& Orthel, 2011) than do men.

An eclectic literature signals that desirable, healthy outcomes are often linked to positive friendship involvement in emerging adulthood, with the most consistent association being with self-reported happiness (Caunt et al., 2013; Demir et al., 2007). In addition, research shows that friendship in emerging adulthood is associated with psychological (Almquist et al., 2014) and subjective well-being (Li \& Cheng, 2015), life satisfaction (Babinčák \& Bačová, 2008), health behaviors (Helgeson et al., 2014), positive mood (Brannan et al., 2013), and both social (Carbery \& Buhrmester, 1998) and psychological 
(Demir \& Orthel, 2011) need fulfillment. Although many positive outcomes have been found to be associated with friendship involvement in emerging adulthood, there has been a recent call for additional study in this area ( $\mathrm{Li} \&$ Cheng, 2015), due to the need for more research analyzing additional outcomes, gender differences, and cultural distinctions. The majority of research that analyzes the effects of friendship engagement on emerging adults focuses on happiness as the primary (or only) outcome; for this reason, potential explanations for why friendship characteristics are linked to happiness will be discussed. For instance, some research suggests that friendships engender a sense of mattering (Demir, Özen, Doğan, Bilyk, \& Tyrell, 2011) and/or a sense of uniqueness (Demir, Şimşek, \& Procsal, 2013) in an individual. Other research proposes there are certain features of friendships, namely companionship and validation (Demir \& Weitekamp, 2007), that are most important to those involved in a friendship; indeed, it may be that having friends provides emerging adults with a sense of security, which enables feelings of happiness. Beyond these interpretations, it is also possible that engaging in activities with friends makes experiences more meaningful, resulting in greater happiness, or it could be that engaging in friendships during emerging adulthood offers individuals a sense of belonging, which has been tied to happiness in other research (Leung, Kier, Fung, Fung, \& Sproule, 2011). Though there are many hypothetical explanations for the existence of the relationships between friendship and happiness, each needs to be further investigated. Specifically, scholars should perform future research in this area that investigates potential mediators / moderators that help account for the relationship between friendship and positive outcomes.

\section{A Conclusion}

The purpose of this chapter was to examine the role that relationships with members of one's family of origin (parents, grandparents, and siblings) and with peers (romantic partners, spouses, and friends) play in flourishing during emerging adulthood. The research reviewed in the chapter makes it clear that some relationships (e.g., parents) have received greater attention than others (e.g., siblings) in research aimed at examining factors tied to positive development in emerging adulthood. Taken together, however, the existing work gives reason to 
believe that relationships with family and peers can play significant roles in the lives of emerging adults, and it therefore underscores the need for more work in this area. A major task of the third decade of life is for young people to become more self-reliant, so it is rather ironic to see the extent to which this requires relationships with others. Indeed, it is rather clear from the work reviewed that coming to stand on one's own is achieved most successfully when it is done within relationships with meaningful others.

\section{A References}

Adamczyk, K., \& Segrin, C. (2014). Perceived social support and mental health among single vs. partnered polish young adults. Current Psychology, 34(1), 82-96.

Almquist, Y. B., Östberg, V., Rostila, M., Edling, C., \& Rydgren, J. (2014). Friendship network characteristics and psychological well-being in late adolescence: Exploring differences by gender and gender composition. Scandinavian Journal of Public Health, 42(2), 146-154.

Amato, P. R. (1994). Father-child relations, mother-child relations, and offspring psychological well-being in early adulthood. Journal of Marriage and the Family, 56(4), 1031-1042. doi:10.2307/353611

Aquilino, W. S. (1997). From adolescent to young adulthood: A prospective study of parent-child relations during the transition to adulthood. Journal of Marriage and the Family, 59, 670-686.

Aquilino, W. S. (2006). Family relationships and support systems in emerging adulthood. In J. J. Arnett, J. L. Tanner, J. J. Arnett, \& J. L. Tanner (Eds.), Emerging adults in America: Coming of age in the 21st century (pp. 193-217). Washington, DC: American Psychological Association.

Attar-Schwartz, S. (2015). Emotional closeness to parents and grandparents: A moderated mediation model predicting adolescent adjustment. American Journal of Orthopsychiatry, 85(5), 495-503. doi:10.1037/ort0000082

Babinčák, P., \& Bačová, V. (2008). Life satisfaction, beliefs, and relations to oneself and others in university students. Studia Psychologica, 50(1), 79-94.

Barber, B. K., \& Harmon, E. L. (2002). Violating the self: Parental psychological control of children and adolescents. In B. K. Barber (Ed.), Psychological control of children and adolescents (pp. 15-52). Washington, DC: American Psychological Association.

Barry, C. M., Chiravalloti, L., May, E., \& Madsen, S. D. (2013). Emerging adults' psychosocial adjustment: Does a best friend's gender matter? Psi Chi Journal of Psychological Research, 18(3), 94-102.

Barry, C. M., Madsen, S. D., Nelson, L. J., Carroll, J. S., \& Badger, S. (2009). Friendship and romantic relationship qualities in emerging adulthood: Differential associations with identity development and achieved adulthood criteria. Journal of Adult Development, 16(4), 209-222. 
Barry, C. M., Padilla-Walker, L. M., Madsen, S. D., \& Nelson, L. J. (2008). The impact of maternal relationship quality on emerging adults' prosocial tendencies: Indirect effects via regulation of prosocial values. Journal of Youth and Adolescence, 37, 581-591.

Barry, C. M., Padilla-Walker, L. M., \& Nelson, L. J. (2012). The role of mothers and media on emerging adults' religious faith and practices by way of internalization of prosocial values. Journal of Adult Development, 19(2), 66-78.

Berge, J. M., Bauer, K. W., MacLehose, R., Eisenberg, M. E., \& Neumark-Sztainer, D. (2014). Associations between relationship status and day-to-day health behaviors and weight among diverse young adults. Families, Systems, $\mathcal{E}$ Health, 32(1), 67.

Berndt, T. J. (2002). Friendship quality and social development. Current Directions in Psychological Science, 11(1), 7.

Block, C. E. (2002). College students' perceptions of social support from grandmothers and stepgrandmothers. College Student Journal, 36(3), 419-432.

Boerner, K., Jopp, D. S., Carr, D., Sosinsky, L., \& Kim, S. K. (2014). "His" and "her" marriage? The role of positive and negative marital characteristics in global marital satisfaction among older adults. Journals of Gerontology Series B: Psychological Sciences and Social Sciences, 69(4), 579-589.

Braithwaite, S. R., Delevi, R., \& Fincham, F. D. (2010). Romantic relationships and the physical and mental health of college students. Personal Relationships, 17(1), 1-12.

Brannan, D., Biswas-Diener, R., Mohr, C. D., Mortazavi, S., \& Stein, N. (2013). Friends and family: A cross-cultural investigation of social support and subjective well-being among college students. Journal of Positive Psychology, 8(1), 65-75. doi:10.1080/17439760.2012.743573

Brook, J. S., Brook, D. W., \& Whiteman, M. (1999). Older sibling correlates of younger sibling drug use in the context of parent-child relations. Genetic, Social, and General Psychology Monographs, 125(4), 451-468.

Campbell, A. (2008). The morning after the night before. Human Nature, 19(2), 157-173. doi:10.1007/s12110-008-9036-2

Campione-Barr, N., Lindell, A. K., Giron, S. E., Killoren, S. E., \& Greer, K. B. (2015). Domain differentiated disclosure to mothers and siblings and associations with sibling relationship quality and youth emotional adjustment. Developmental Psychology, 51(9), 1278-1291. doi:10.1037/dev0000036

Cantor, M. H. (1979). Neighbors and friends: An overlooked resource in the informal support system. Research on Aging, 1, 434-463. doi: 10.1177/ 016402757914002.

Carbery, J., \& Buhrmester, D. (1998). Friendship and need fulfillment during three phases of young adulthood. Journal of Social and Personal Relationships, 15, 393-409.

Carmichael, C. L., Reis, H. T., \& Duberstein, P. R. (2015). In your 20s it's quantity, in your 30s it's quality: The prognostic value of social activity across 30 years of adulthood. Psychology and Aging, 30(1), 95-105. doi:10.1037/ pag0000014

Carver, K., Joyner, K., \& Udry, J. R. (2003). National estimates of adolescent romantic relationships. In P. Florsheim (Eds.), Adolescent romantic relations 
and sexual behavior: Theory, research, and practical implications (pp 23-56). Mahwah, NJ: Lawrence Erlbaum.

Caunt, B. S., Franklin, J., Brodaty, N. E., \& Brodaty, H. (2013). Exploring the causes of subjective well-being: A content analysis of peoples' recipes for long-term happiness. Journal of Happiness Studies, 14(2), 475-499.

Cerdá, M., Bordelois, P., Keyes, K. M., Roberts, A. L., Martins, S. S., Reisner, S. L., . . Koenen, K. C. (2014). Family ties: Maternal-offspring attachment and young adult nonmedical prescription opioid use. Drug and Alcohol Dependence, 142, 231-238. doi:10.1016/j.drugalcdep.2014.06.026

Cheng, H., \& Furnham, A. (2003). Personality, self-esteem, and demographic predictions of happiness and depression. Personality and Individual Differences, 34(6), 921-942.

Chow, H. H. (2005). Life satisfaction among university students in a Canadian prairie city: A multivariate analysis. Social Indicators Research, 70(2), 139150. doi:10.1007/s11205-004-7526-0

Collibee, C., \& Furman, W. (2015). Quality counts: Developmental shifts in associations between romantic relationship qualities and psychosocial adjustment. Child Development, 86(5), 1639-1652.

Crocetti, E., \& Meeus, W. (2014). “Family comes first!" Relationships with family and friends in Italian emerging adults. Journal of Adolescence, 37(8), 14631473. doi:10.1016/j.adolescence.2014.02.012

Csikszentmihalyi, M., \& Hunter, J. (2003). Happiness in everyday life: The uses of experience sampling. Journal of Happiness Studies, 4(2), 185-199.

Cutrona, C. E., Cole, V., Colangelo, N., Assouline, S. G., \& Russell, D. W. (1994). Perceived parental social support and academic achievement: An attachment theory perspective. Journal of Personality $\mathcal{E}$ Social Psychology, 66(2), 369-378.

Demir, M. (2008). Sweetheart, you really make me happy: Romantic relationship quality and personality as predictors of happiness among emerging adults. Journal of Happiness Studies, 9(2), 257-277. doi:10.1007/s10902-007-9051-8

Demir, M. (2010). Close relationships and happiness among emerging adults. Journal of Happiness Studies, 11(3), 293-313. doi:10.1007/s10902-009-9141-x

Demir, M., Jaafar, J., Bilyk, N., \& Mohd Ariff, M. R. (2012). Social skills, friendship and happiness: A cross-cultural investigation. Journal of Social Psychology, 152(3), 379-385.

Demir, M., \& Orthel, H. (2011). Friendship, real-ideal discrepancies, and well-being: Gender differences in college students. Journal of Psychology: Interdisciplinary and Applied, 145(3), 173-193. doi:10.1080/ 00223980.2010 .548413

Demir, M., Özdemir, M., \& Weitekamp, L. A. (2007). Looking to happy tomorrows with friends: Best and close friendships as they predict happiness. Journal of Happiness Studies, 8(2), 243-271.

Demir, M., Özen, A., Doğan, A., Bilyk, N. A., \& Tyrell, F. A. (2011). I matter to my friend, therefore I am happy: Friendship, mattering, and happiness. Journal of Happiness Studies, 12(6), 983-1005.

Demir, M., Şimşek, Ö. F., \& Procsal, A. D. (2013). I am so happy 'cause my best friend makes me feel unique: Friendship, personal sense of uniqueness and happiness. Journal of Happiness Studies, 14(4), 1201-1224. 
Demir, M., \& Weitekamp, L. A. (2007). I am so happy 'cause today I found my friend: Friendship and personality as predictors of happiness. Journal of Happiness Studies, 8, 181-211

Ducat, W. H., \& Zimmer-Gembeck, M. J. (2010). Romantic partner behaviours as social context: Measuring six dimensions of relationships. Journal of Relationships Research, 1(1), 1-16.

Eccles, J., Templeton, J., Barber, B., \& Stone, M. (2003). Adolescence and emerging adulthood: The critical passage ways to adulthood. In M. H. Bornstein, L. Davidson, C. M. Keyes, K. A. Moore, M. H. Bornstein, L. Davidson, . . . K. A. Moore (Eds.), Well-being: Positive development across the life course (pp. 383-406). Mahwah, NJ: Lawrence Erlbaum.

Elliott, M. (1996). Impact of work, family, and welfare receipt on women's selfesteem in young adulthood. Social Psychology Quarterly, 59(1), 80-95.

Englund, M. M., Kuo, S. I., Puig, J., \& Collins, W. A. (2011). Early roots of adult competence: The significance of close relationships from infancy to early adulthood. International Journal of Behavioral Development, 35(6), 490-496. doi:10.1177/0165025411422994

Eshbaugh, E. M., \& Gute, G. (2008). Hookups and sexual regret among college women. Journal of Social Psychology, 148(1), 77-90.

Fraley, R. C., \& Roisman, G. I. (2015). Early attachment experiences and romantic functioning: Developmental pathways, emerging issues, and future directions. In J. A. Simpson, W. S. Rholes, J. A. Simpson, W. S. Rholes (Eds.), Attachment theory and research: New directions and emerging themes (pp. 9-38). New York, NY: Guilford Press.

Fuligni, A. J., \& Pedersen, S. (2002). Family obligation and the transition to young adulthood. Developmental Psychology, 38(5), 856.

Furman, W., \& Collibee, C. (2014). A matter of timing: Developmental theories of romantic involvement and psychosocial adjustment. Development and Psychopathology, 26(4 pt. 1), 1149-1160.

Gala, J., \& Kapadia, S. (2013). Romantic relationships in emerging adulthood: A developmental perspective. Psychological Studies, 58(4), 406-418. doi:10.1007/s12646-013-0219-5s

Galambos, N. L., Barker, E. T., \& Krahn, H. J. (2006). Depression, self-esteem, and anger in emerging adulthood: Seven-year trajectories. Developmental Psychology, 42(2), 350-365. doi:10.1037/0012-1649.42.2.350

Garcia, A., Pereira, F. N., \& de Macedo, M. D. C. (2015). Friendship and happiness in Latin America: A review. In M. Demir (Ed.), Friendship and Happiness (pp. 225-234). Dordrecht, The Netherlands, Springer.

Grello, C. M., Welsh, D. P., \& Harper, M. S. (2006). No strings attached: The nature of casual sex in college students. Journal of Sex Research, 43(3), 255-267.

Hamilton, V. E. (2012). The age of marital capacity: Reconsidering civil recognition of adolescent marriage. Boston University Law Review, 92(6), 1817-1863.

Helgeson, V. S., Palladino, D. K., Reynolds, K. A., Becker, D. J., Escobar, O., \& Siminerio, L. (2014). Relationships and health among emerging adults with and without type 1 diabetes. Health Psychology, 33(10), 1125. 
Henderson, C. E., Hayslip, B., Sanders, L. M., \& Louden, L. (2009). Grandmothergrandchild relationship quality predicts psychological adjustment among youth from divorced families. Journal of Family Issues, 30(9), 1245-1264.

Holahan, C. J., Valentiner, D. P., \& Moos, R. H. (1994). Parental support and psychological adjustment during the transition to young adulthood in a college sample. Journal of Family Psychology, 8(2), 215.

Hollifield, C. R., \& Conger, K. J. (2015). The role of siblings and psychological needs in predicting life satisfaction during emerging adulthood. Emerging Adulthood, 3(3), 143-153. doi:10.1177/2167696814561544

Hymowitz, K. S., Carroll, J. S., \& Wilcox, W. B. (2013). Knot yet: The benefits and costs of delayed marriage in America. National Marriage Project at the University of Virginia. Retrieved from twentysomethingmarriage.org

Johnson, M. D. (2013). Parent-child relationship quality directly and indirectly influences hooking up behavior reported in young adulthood through alcohol use in adolescence. Archives of Sexual Behavior, 42(8), 1463-1472. doi:10.1007/s10508-013-0098-9

Jonason, P. K., Li, N. P., \& Cason, M. J. (2009). The "booty call": A compromise between men's and women's ideal mating strategies. Journal of Sex Research, $46,1-11$.

Keel, P. K., Baxter, M. G., Heatherton, T. F., \& Joiner, T. E., Jr. (2007). A 20-year longitudinal study of body weight, dieting, and eating disorder symptoms. Journal of Abnormal Psychology, 116(2), 422.

Laible, D. J., Carlo, G., \& Roesch, S. C. (2004). Pathways to self-esteem in late adolescence: The role of parent and peer attachment, empathy, and social behaviours. Journal of Adolescence, 27(6), 703-716. doi:10.1016/ j.adolescence.2004.05.005

Langer, N., \& Ribarich, M. (2007). Aunts, uncles-nieces, nephews: Kinship relations over the lifespan. Educational Gerontology, 33(1), 75-83.

Leung, A., Kier, C., Fung, T., Fung, L. \& Sproule, R. (2011). Searching for happiness: The importance of social capital. Journal of Happiness Studies, 12(3), 443-462.

Li, T., \& Cheng, S. T. (2015). Family, friends, and subjective well-being: A comparison between the West and Asia. In M. Demir (Ed.), Friendship and Happiness (pp. 235-251). Dordrecht, The Netherlands, Springer.

Luyckx, K., Soenens, B., Vansteenkiste, M., Goossens, L., \& Berzonsky, M. D. (2007). Parental psychological control and dimensions of identity formation in emerging adulthood. Journal of Family Psychology, 21(3), 546-550.

Mansson, D. H. (2013). College students' mental health and their received affection from their grandparents. Communication Research Reports, 30(2), 157-168.

Mansson, D. H., \& Booth-Butterfield, M. (2011). Grandparents' expressions of affection for their grandchildren: Examining grandchildren's relational attitudes and behaviors. Southern Communication Journal, 76(5), 424-442. doi:10.1080/1041794x.2010.508554

Mernitz, S. E., \& Dush, C. K. (2016). Emotional health across the transition to first and second unions among emerging adults. Journal of Family Psychology, 30(2), 233-244. doi:10.1037/fam0000159 
Messeri, P., Silverstein, M., \& Litwak, E. (1993). Choosing optimal support groups: A review and reformulation. Journal of Health and Social Behavior, 34, 122-137. doi:10.2307/2137239.

Milevsky, A. (2005). Compensatory patterns of sibling support in emerging adulthood: Variations in loneliness, self-esteem, depression and life satisfaction. Journal of Social and Personal Relationships, 22(6), 743-755. doi:10.1177/ 0265407505056447

Nelson, L. J., \& Padilla-Walker, L. M. (2013). Flourishing and floundering in emerging-adult college students. Emerging Adulthood, 1, 67-78.

Nelson, L. J., Padilla-Walker, L. M., Christensen, K. J., Evans, C. A., \& Carroll, J. S. (2011). Parenting in emerging adulthood: An examination of parenting clusters and correlates. Journal of Youth and Adolescence, 40, 730-743.

Owen, J., Fincham, F. D., \& Moore, J. (2011). Short-term prospective study of hooking up among college students. Archives of Sexual Behavior, 40(2), 331-341.

Padilla-Walker, L. M., \& Nelson. L. J. (2012). Black Hawk down? Establishing helicopter parenting as a distinct construct from other forms of parental control during emerging adulthood. Journal of Adolescence, 35, 1177-1190.

Padilla-Walker, L. M., Nelson, L. J., \& Knapp, D. (2014). “Because I'm still the parent, that's why!" Parental legitimate authority among emerging adult college students. Journal of Social and Personal Relationships, 31, 293-313.

Ponti, L., Guarnieri, S., Smorti, A., \& Tani, F. (2010). A measure for the study of friendship and romantic relationship quality from adolescence to earlyadulthood. Open Psychology Journal, 3(1), 76-87.

Ralston, E. S., Trudeau, L. S., \& Spoth, R. (2012). Effects of parent-child affective quality during high school years on subsequent substance use. International Journal of Emotional Education, 4(1), 25-42.

Ratelle, C. F., Simard, K., \& Guay, F. (2013). University students' subjective well-being: The role of autonomy support from parents, friends, and the romantic partner. Journal of Happiness Studies, 14(3), 893-910. doi:10.1007/ s10902-012-9360-4

Rhoades, G. K., Stanley, S. M., \& Markman, H. J. (2006). Pre-engagement cohabitation and gender asymmetry in marital commitment. Journal of Family Psychology, 20(4), 553.

Ruiz, S. A., \& Silverstein, M. (2007). Relationships with grandparents and the emotional well-being of late adolescent and young adult grandchildren. Journal of Social Issues, 63(4), 793-808.

Scharf, M. (2015). Maturing and aging together: Emerging adult grandchildren-grandparents relationships. In J. J. Arnett (Ed.), The Oxford handbook of emerging adulthood (pp. 203-212). New York, NY: Oxford University Press.

Scharf, M., \& Shulman, S. (2015). Closeness, distance, and rapprochement in sibling relationships. In J. J. Arnett (Ed.), The Oxford handbook of emerging adulthood (pp. 190-202). New York, NY: Oxford University Press.

Schiffrin, H. H., Liss, M., Miles-McLean, H., Geary, K. A., Erchull, M. J., \& Tashner, T. (2014). Helping or hovering? The effects of helicopter parenting on college students' well-being. Journal of Child and Family Studies, 23(3), 548-557. 
Scott, K. M., Wells, J. E., Angermeyer, M., Brugha, T. S., Bromet, E., Demyttenaere, K., . . Karam, A. N. (2010). Gender and the relationship between marital status and first onset of mood, anxiety and substance use disorders. Psychological Medicine, 40(9), 1495-1505.

Segrin, C., Woszidlo, A., Givertz, M., Bauer, A., \& Murphy, M. T. (2012). The association between overparenting, parent-child communication, and entitlement and adaptive traits in adult children. Family Relations, 61, 237-252. doi:10.1111/j.1741-3729.2011.00689.x

Settersten, R. A., \& Ray, B. (2010). What's going on with young people today? The long and twisted path to adulthood. Future of Children, 20, 19-41.

Serido, J., Lawry, C., Li, G., Conger, K. J., \& Russell, S. T. (2014). The associations of financial stress and parenting support factors with alcohol behaviors during young adulthood. Journal of Family and Economic Issues, 35(3), 339 350. doi:10.1007/s10834-013-9376-x

Sheehan, N. W., \& Petrovic, K. (2008). Grandparents and their adult grandchildren: Recurring themes from the literature. Marriage \& Family Review, 44(1), 99-124.

Sheets, R. J., \& Mohr, J. J. (2009). Perceived social support from friends and family and psychosocial functioning in bisexual young adult college students. Journal of Counseling Psychology, 56(1), 152-163. doi:10.1037/ 0022-0167.56.1.152

Sherman, A. M., Lansford, J. E., \& Volling, B. L. (2006). Sibling relationships and best friendships in young adulthood: Warmth, conflict, and well-being. Personal Relationships, 13(2), 151-165. doi:10.1111/ j.1475-6811.2006.00110.x

Simon, R. W., \& Barrett, A. E. (2010). Nonmarital romantic relationships and mental health in early adulthood: Does the association differ for women and men? Journal of Health and Social Behavior, 51(2), 168-182. doi:10.1177/ 0022146510372343

Simons, R. L. (1983). Specificity and substitution in the social networks of the elderly. International Journal of Aging and Human Development, 18(2), 121-139.

Soons, J. P., \& Liefbroer, A. C. (2008). Together is better? Effects of relationship status and resources on young adults' well-being. Journal of Social and Personal Relationships, 25(4), 603-624.

Stack, S., \& Eshleman, J. R. (1998). Marital status and happiness: A 17-nation study. Journal of Marriage and the Family, 60, 527-636.

Tanner, J. L. (2011). Emerging adulthood. In R. J. R. Levesque (Ed.), Encyclopedia of Adolescence (pp. 818-825). New York: Springer.

Tanskanen, A. O., \& Danielsbacka, M. (2012). Beneficial effects of grandparental involvement vary by lineage in the UK. Personality and Individual Differences, 53(8), 985-988.

Taylor, R. J., Chatters, L. M., Hardison, C. B., \& Riley, A. (2001). Informal social support networks and subjective well-being among African Americans. Journal of Black Psychology, 27, 439-463.

Urry, S., Nelson, L. J., \& Padilla-Walker, L. M. (2011). Mother knows best: Psychological control, child disclosure, and maternal knowledge in emerging adulthood. Journal of Family Studies, 17, 157-173. 
Van der Giessen, D., Branje, S., \& Meeus, W. (2014). Perceived autonomy support from parents and best friends: Longitudinal associations with adolescents' depressive symptoms. Social Development, 23(3), 537-555. doi:10.1111/ sode.12061

van Wel, F., Linssen, H., \& Abma, R. (2000). The parental bond and the wellbeing of adolescents and young adults. Journal of Youth and Adolescence, 29, 307-318.

Whitbeck, L., Hoyt, D. R., \& Huck, S. M. (1994). Early family relationships, intergenerational solidarity, and support provided to parents by their adult children. Journal of Gerontology, 49(2), S85-S94.

Whitton, S. W., \& Kuryluk, A. D. (2012). Relationship satisfaction and depressive symptoms in emerging adults: Cross-sectional associations and moderating effects of relationship characteristics. Journal of Family Psychology, 26(2), 226-235. doi:10.1037/a0027267

Whitton, S. W., Weitbrecht, E. M., Kuryluk, A. D., \& Bruner, M. R. (2013). Committed dating relationships and mental health among college students. Journal of American College Health, 61(3), 176-183.

Willeto, A. P. A. A. (2015). Friendship and happiness in Navajos (Bik'éí Diné Baa'Hózhó). In M. Demir (Ed.), Friendship and Happiness (pp. 209-223). Dordrecht, The Netherlands, Springer.

Willoughby, B. J., \& Hall, S. S. (2015). Enthusiasts, delayers, and the ambiguous middle: Marital paradigms among emerging adults. Emerging Adulthood, 3(2), 123-135.

Willoughby, B. J., Hersh, J., Padilla-Walker, L. M., \& Nelson, L. J. (2015). “Back off!" Helicopter parenting and a retreat from marriage among emerging adults. Journal of Family Issues, 36, 669-692.

Wintre, M. G., \& Yaffe, M. (2000). First-year students' adjustment to university life as a function of relationships with parents. Journal of Adolescent Research, 15(1), 9-37.

Wood, R. G., Goesling, B., \& Avellar, S. (2007). The effects of marriage on health: A synthesis of recent research evidence. Washington DC: Mathematica Policy Research, Inc. Retrieved from https://aspe.hhs.gov/sites/default/ files/pdf/75106/report.pdf

Yorgason, J. B., Padilla-Walker, L., \& Jackson, J. (2011). Nonresidential grandparents' emotional and financial involvement in relation to early adolescent grandchild outcomes. Journal of Research on Adolescence, 21(3), 552-558.

Yu, R., Branje, S., Keijsers, L., \& Meeus, W. (2015). Associations between young adult romantic relationship quality and problem behaviors: An examination of personality-environment interactions. Journal of Research in Personality, 57, 1-10. doi:10.1016/j.jrp.2015.01.003 